\title{
Life Cycle BIM-Oriented Data \\ Collection: A Framework for Supporting Practitioners
}

\author{
Anna Dalla Valle, Andrea Campioli and Monica Lavagna
}

\begin{abstract}
For updating the construction sector in line with current trends, Life Cycle Thinking (LCT) has to be integrated into the building process from the beginning. In this perspective, the digitalization increasingly assists practitioners in the task, taking advantage in particular of the now widespread Building Information Modeling (BIM). To face construction challenges, the research suggests conceiving BIM as a life cycle database that evolves over time in conjunction with building process development. In this way, to support the players involved in the shift both in thinking and in process, the result of the research is a data collection framework that activates over the process a rigorous life cycle oriented information flow to build up the expected life cycle project-based BIM database. Indeed, since to guarantee the effectiveness of the digitalization process collaboration environments, each stakeholder has to know the requirements of the information content, it points out, based on current practice, the set of life cycle information, the actors in charge and the derived life cycle information flow demanded during the process. The aim is to establish, in one single BIM record, a project-based and well-framed set of data of the facility during the whole life cycle.
\end{abstract}

Keywords Life Cycle Thinking $\cdot$ Building Information Modeling $\cdot$ Life cycle database $\cdot$ Information flow

\footnotetext{
A. Dalla Valle (凶) · A. Campioli · M. Lavagna

Architecture, Built Environment and Construction Engineering-ABC Department, Politecnico di Milano, Milan, Italy

e-mail: anna.dalla@polimi.it

(C) The Author(s) 2020

B. Daniotti et al. (eds.), Digital Transformation of the Design, Construction and Management Processes of the Built Environment, Research for Development, https://doi.org/10.1007/978-3-030-33570-0_5
} 


\section{Change of Paradigm of BIM Toward LCT}

To handle buildings as complex systems, the construction sector is increasingly confronted with a BIM approach. However, to face sustainable goals straight away, it should be complemented with LCT and related methodologies, which are now recognized as pivotal in improving resource efficiency with environmental, social and economic benefits (UN environment 2018). There is the need to shift the shared mental model of buildings from stuff (i.e., products and technologies) to purposeful systems- and life cycle-thinking (Boecker et al. 2009; Rusu and Popescu 2018).

In this perspective, the advancement of technology, computation, and digitalization consistently boosts the transition of the building sector in that direction (Jiao et al. 2013). A wide range of methodologies and tools is now available to help practitioners in the understanding of buildings as systems and as parts of a larger system of their context, extending thus their influence beyond the site and toward the whole environment (Rezgui et al. 2011; Riese 2012; Chirjiv and Ben 2017). Moreover, as anticipated, BIM is adopted even more in design and construction practice to address the challenging tasks which characterize the building sector (Becerik and Kensek 2010; Dupuis et al. 2017). Despite the technological, cultural, and legal barriers, the great potential offered by BIM is that it is conceived as a database that embeds, displays, and calculates graphical/tangible and non-graphical/intangible information, ensuring the connection of information and data to the related objects. These functionalities appear pivotal in providing a reliable basis for decisions during the whole building life cycle, especially because, serving as a shared resource for information, it encourages communication, collaboration, and cooperation across the broad spectrum of disciplines and stakeholders involved in the process (Succar and Kassem 2015). Nevertheless, since BIM is tailored to fit a multitude of practices and projects, if, on one hand, it allows maximum flexibility to practitioners, on the other, it requires considerable effort to customize and arrange all the data in an efficient and effective way. For this reason, industry players agree that they are only just beginning to explore the full capabilities of BIM, claiming to achieve far more than they currently do (McGraw Hill Construction 2009), regarding, for instance, the amount of data and information included in the building model.

In this context, to support building practitioners toward the requested system- and life cycle-thinking, the paper shows a data collection framework aimed at creating a life cycle project-based BIM database (Dalla Valle et al. 2018). It is the result of a 3-year research project, based on the in-depth analysis of current practice taking, in line with construction trends, a life cycle perspective. Indeed, to face the forthcoming construction challenges, it emerges the need for a change of paradigm in the conception of BIM towards LCT. To take full advantage of the potential of digitalization, BIM has to be advanced from a database that evolves over the building life cycle in terms of quality and quantity to a life cycle database that properly progresses over time from its inception onward. The transition of BIM into a building life cycle database consists of the integration of the life cycle information content into the model showing, as normally happens as the phases are perfected, different degrees 
of depth (detail), stability (development), and reliability (approval). The improvement during the process of the set of intangible information attached to the tangible BIM objects and model with the related life cycle information and data has a dual objective. First, from the outset it provides additional specifications on the selected technological elements, not limiting them to the construction phase but involving their entire life cycle. Second, it reveals and traces the set of criteria adopted during the decision-making of the whole building process, expanding the typical performance and aesthetic parameters with the connected life cycle information to make aware decisions, avoid shifting problems and gain a long-term perspective.

The paper therefore presents the data collection framework that, by organizing the required life cycle information and actors in charge and envisioning the resulting information flow during the process, supports in practice construction players in the establishment and development of their life cycle BIM database, creating over time a valuable source of information for all the stakeholders involved in the building process.

\section{Joining Life Cycle Information, Building Elements and Actors}

The data collection framework is based on the list of life cycle information required for performing building Life Cycle Assessment (LCA) studies (EN 15978: 2011; EPD PCR UN CPC 531: 2014). In this way, LCT, which represents a general mindset, is explained taking as a reference frame LCA, providing an added value since it depicts an international standardized methodology. However, it is important to stress that the paper focuses only on the data collection of "foreground systems" (EC-JRC 2012), involving the set of quantitative information since directly demanded by building practitioners and therefore to bear in mind during the process. The environmental information of the "background system" are thus actually omitted, since they are not tied to practice but rather attributed to literature, external database (e.g. Ecoinvent) or primary data (e.g. EPD).

Once re-elaborated from the standards, the life cycle information are revealed by the data collection framework, referring them to the main technological elements in question at the building level. In particular, for construction materials they concern: structure, cladding, envelope, walls, floors, finishes, equipment, and furnishing; while for building systems they concern: HVAC, plumbing, electrical, and renewables systems. Each life cycle information is thus further detailed in terms of the technological elements involved, in some cases encompassing them in their entirety (e.g. transport) while in others partially, since the life cycle topic affects only certain building elements (e.g. maintenance).

Besides the systematic arrangement of the life cycle information breakdown in the connected technological elements, the data collection framework promotes their 
progressive implementation into the expected life cycle BIM database from the beginning of the process: the design phase. Indeed, it figures out the life cycle information for each design subphase according to the process development of current practice, explored through an ethographic approach (Pink et al. 2013), joining an internationally affirmed architectural and engineering firm and analyzing a sample of representative case studies. In this way, the data collection framework specifies to practitioners the information to be collected in each phase, distinguishing the ones already considered in practice, based on the decision-making of the reference projects, from the ones to be implemented to turn into a life cycle oriented practice. Concerning the latter, the targeting of the life cycle information is established depending on the information and requirements now available and outlining the associated life cycle topics to be included in the different process phases.

Based on the progressive information setup, narrowed-due to the partnership agreement - on the design process, the data collection framework entrusts the design team with integrating into BIM right from the beginning the advised life cycle information and data according to the specific phase in progress. In this way, the aim is to orient the whole decision-making in line with life cycle perspective, soliciting not only a gradual implementation but also a growing level of detail and accuracy of the life cycle information in conjunction with the process development. In fact, to boost the optimization of the process, the whole set of life cycle data, inputted following the data collection framework recommendations, turn out to be the thresholds not to be exceeded in the subsequent process phases.

In addition, due to the broad spectrum of information required toward LCT and the wide range of competencies involved in the building design process, the data collection framework is structured in such a way that the roles of gathering the recommended life cycle information are shared with the main design competences. The actors in charge are explained in accordance with a recognized classification (Omniclass 2012), joining them with the highlighted technological elements based on current practice. In particular, they involve: architecture for cladding, envelope, walls and floor; interior design for furnishing; health/laboratory design for equipment; structural engineering for structure; mechanical engineering for HVAC systems; plumbing engineering for plumbing systems; electrical engineering for electrical systems; building energy design for renewables systems and building operational energy use; and environmental design/sustainability for building operational water use. In this way, the joint combination of all individual efforts allows to obtain an overall and systemic vision of the designed building, resulting in the life cycle BIM database with the associated opportunities offered (Fig. 1).

Indeed, all these competencies are assigned to design the related technological elements including life cycle information as further criteria of the decision-making, as prescribed by the data collection framework, contributing to and extracting information from BIM. In this perspective, to encourage the different team of actors in adopting a systemic approach towards life cycle design, personal worksheets are inferred for each competence from the data collection framework, setting out the information required at each phase of the process for each assigned technological element. The worksheets thus enable each individual actor to become aware of the 


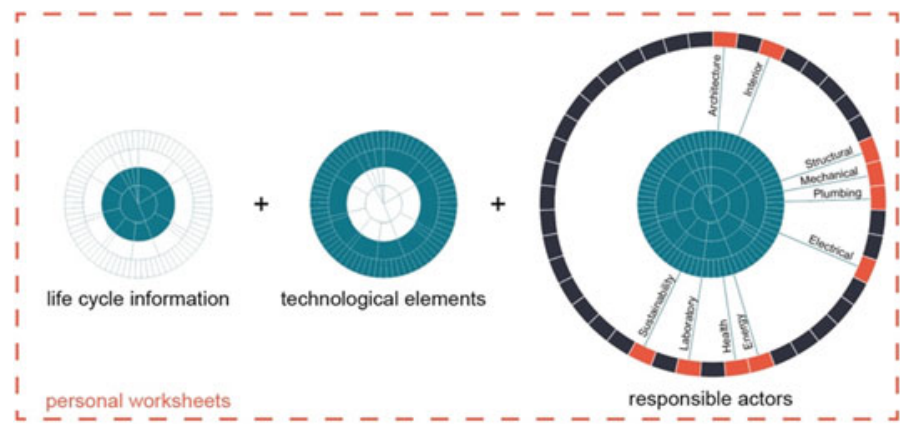

Fig. 1 Relationships of information, elements, and actors toward life cycle data collection

life cycle information and data under their responsibility and of their step-by-step collection to create the life cycle BIM database. In this manner, they simultaneously affect the decision-making process, calling upon the practitioners involved to find design solutions by accounting for the listed life cycle information and data.

\section{Life Cycle Information Flow During the Process}

Appointing the specific design competencies as responsible for the defined life cycle information, the proposed data collection framework activates, during the process, a rigorous life cycle-oriented information flow to build up a project-based life cycle database within a BIM working environment. To this end, it is important to underline a key strength compared to current design practice. Indeed, even today very little life cycle information are actually ever considered in practice by the design team, although they are exchanged in one-to-one relationships and cited fragmentarily in various supporting documents. By contrast, following the data collection framework, all the responsible actors enter the entire set of life cycle information and data into the life cycle BIM database of the facility. In this way, all life cycle information are collected in one single record, enabling all practitioners not only to fill in their assigned information but also easily to find all the available data for the widest range of purposes (Fig. 2).

To provide a synopsis, the following paragraphs illustrate the information flow demanded by the data collection framework to build up the life cycle BIM database, pointing out for each phase of the design process the overall set of actors involved with the committed life cycle information. In this connection, note that the assigned life cycle information are tailored to the requirements and level of detail achieved in the specific phase in question (DVA 2010) and that the engaged actors represent the main competencies that have to be supported, foremost to integrate LCT into the construction sector starting from the early phases of the process. 


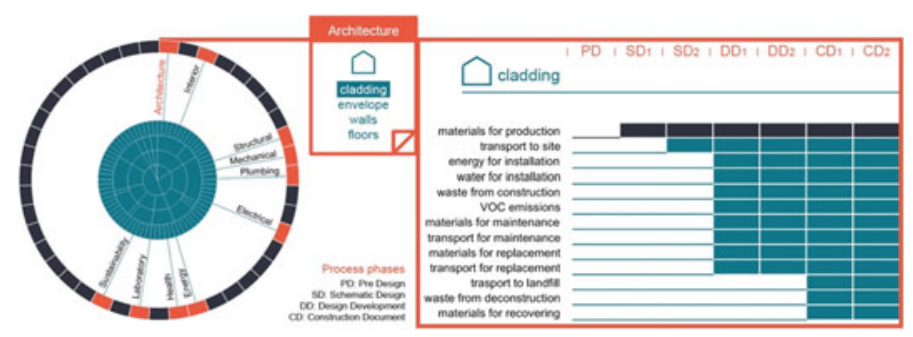

Fig. 2 Life cycle information of cladding assigned to architecture during the process

\subsection{Pre-design Phase}

The pre-design phase represents a crucial step, especially for the definition of the project sustainability goals to be pursued and reached throughout the whole process. In fact, besides heavily affecting the decision-making process, sustainability goals also have an impact on the building life cycle data collection because, being established in conjunction with clients as targets of the project, they compel the design team to consistently check with them the life cycle information and data entered into BIM. In this way, if the data does not comply with the targets set, the team has to call into question the previous design choices, changing at the end the proposed design solutions. For this reason, it is practical to express from the start the sustainability goals in accordance with the list of life cycle information defined by the data collection framework, in order to encourage their monitoring and verification during the project development. Sustainability goals should thus combine the targets commonly set by clients and requirements for the operational phase (e.g. energy use, water use, and greenhouse gas emission reduction), with the ones relevant to the other life cycle phases (e.g. construction waste and recycling materials), taking as reference the thresholds set by the various Green Building Rating Systems criteria and Green Public Procurement requirements.

Concerning the required life cycle information flow, due to the very preliminary state of the project, it involves few competences and a limited set of life cycle information. Indeed, in this phase the design team identifies alternative volumetric solutions, allowing clients to select one of the proposed concepts, outlining the general massing and site location of the facility for further development. In this context, only architecture and building energy design competencies are encouraged by the data collection framework for considering during the decision-making, in the first case, the envelope surface and, in the second, the main building energy consumption for heating, cooling, and lighting systems. However, it is worth mentioning that, since the data collection is conceived within a BIM working environment, these data (although not only) are automatically generated by the building model or related plug-in, avoiding rework and time wasting and improving the coherence of the information provided. 


\subsection{Schematic Design Phase}

During the Schematic Design phase, the life cycle data collection engages all the principal competencies involved in the process and responsible for the design of the main technological elements. In fact, in this phase, the project team develops the approved concept plan, working as appropriate on different spatial and technological alternatives in order to identify the best options for the project at hand. In this way, during design, the actors in charge are committed to an evaluation of different options for the assigned technological elements, involving the selection of a wide range of criteria, including also the life cycle ones.

In particular, the implementation of life cycle information is stressed from the outset for engineering competences, requesting mechanical and electrical engineering as well as building energy design to provide specifications on the maintenance and replacement processes of the proposed solutions, respectively for HVAC, electrical and renewables systems. Instead, since architectural competencies are mainly focused on aesthetic and functional building decisions, only transport distances are demanded as life cycle information for the preliminary cladding solutions. The same happens for structural engineering, called for considering transport distances during the material selection of the proposed structural systems. Moreover, combining the set of early architectural and engineering solutions, building energy design has to estimate the energy consumption of heating, air conditioning, lighting and ventilation systems, as well as the energy generated by renewables systems, showing also the associated emissions. Meanwhile, environmental design/sustainability has to estimate the water consumption of sanitation and irrigation systems. In addition, as a design process within a BIM working environment, all technological solutions are progressively quantified as appropriate in terms of area, volume, item, or linear development, systematically arranging the production information for both construction material and building systems.

\subsection{Design Development Phase}

The design development phase is intended to add an increased level of detail for all aspects of the project to further define the design and the attribute of interior and exterior spaces. In this context, the data collection framework plays a key role in supporting the design team in selecting the set of material solutions most appropriate for the project also from a life cycle perspective, improving and enhancing the accuracy of the collected life cycle information and data.

Indeed, the design team effort is focused on the definition of all technological components, soliciting the team of actors responsible to explore the main life cycle topics and to collect the connected life cycle information and data at least of the typical items. Concerning the project construction stage, architecture has to consider transport distances and construction waste quantity for envelope and cladding and 
structural engineering for building structure. In addition, architecture is in charge of the estimate in overall terms of the energy used for the installation of products and for the water used for on-site production. About the use stage, architecture and interior competencies have to be included for cladding and finish solutions, respectively, the related VOC emissions as well as the materials and transport required for maintenance and replacement operations. The latter information have to be updated also for HVAC, electrical, and renewables systems by the appropriate competencies, represented by mechanical, electrical engineering, and building energy design. Moreover, building energy design has to recalculate, based on the latest design solutions, the operational energy consumption by end-user, considering in detail: heating, air conditioning, hot water supply, ventilation, lighting systems, pumps and auxiliaries and miscellaneous equipment, then compared with the energy generated both by renewable and nonrenewable resources. Likewise, the environmental design/sustainability has to rerun the operational water consumption breakdown in the usage for sanitation, domestic hot water, and irrigation systems. In this way, the resulting life cycle BIM database turns out to be enriched with a broad range of life cycle information, relating to the production, construction, and use stages of the principal technological elements.

\subsection{Construction Document Phase}

During the construction document phase, the project is given further detail by the design team in terms of specific product solutions to provide the necessary documents for bidding. At this point, following the data collection framework, the team is entrusted with completing all the required life cycle information, later converted into the set of specifications to be clearly communicated to the contractor.

To this end, all the previously inputted life cycle information and data are checked, adjusted, and updated both in relation to the design development and to the data sources, opting preferably for primary data of specific products rather than database or literature data. Furthermore, additional life cycle information are required, enlarging the set of technological elements to be considered and the life cycle topics in question. In this way, transport distances are demanded not only for structure, cladding, and envelope components but also for walls, floors, finishes, equipment, furnishing, and for all the main building systems, involving all the competences of reference. The same happens for the amount of construction waste, in which the technological elements included are extended to walls, floors, and finishes, involving in particular architecture and interior design. The latter competences, with the support of health/laboratory design, also have to insert the VOC emissions of cladding, finishes, equipment, and furnishing. Materials and transport distances for maintenance and replacement processes have to be finalized for both the architectural and engineering elements, engaging the different competences according to their respective areas of expertise. With regard to building use consumption, as in the previous phase, the expected operational energy split by end-user has to be reprocessed 
by building energy design in collaboration with mechanical engineering. Instead, the operational water use has to be further specified as follows: by environmental design/sustainability for water sanitation and irrigation systems, by plumbing engineering for domestic hot water and building auxiliaries systems, by mechanical engineering for HVAC systems and by health/laboratory design for the main building appliances. Finally, the end of life stage information has to be implemented involving, on one hand, architecture and interior design for all construction materials and, on the other, mechanical, plumbing, and electrical engineering for all systems materials. These competencies are thus called upon to assess, with reference to the assigned technological elements, the connected transport to landfill, waste derived from the deconstruction process and the potential materials for reuse, recycling, and energy recovery.

\section{Outlook of the Resulting Life Cycle BIM Database}

Established under the proposed data collection framework, the development during the process of the life cycle BIM database has a twofold aim for the construction sector. From the life cycle perspective, it allows a project-based and well-framed set of data of the facility during the whole life cycle to be tracked in one single record, conceived in a BIM working environment. In addition, it appears to be of added value for clients, stakeholders as well as for design firms, enabling a continuous build-up of know-how, not only in terms of the specific life cycle project-based BIM database but also for that of future projects, and also represents the input data especially for Life Cycle Assessment and Life Cycle Costing analysis. By contrast, from the design process perspective, it allows the overall monitoring of the process and the verification of its optimization, since the declared life cycle information and data stand for the thresholds not to be exceeded in the subsequent process phases. Moreover, the data collection framework helps to build sector practitioners to comply with sustainability goals and towards LCT, calling for a life cycle information flow through a sharing of roles and responsibility. However, if on one hand, this organizational setup represents a point of strength, not overburdening design competences in their assignments, on the other, it constitutes a point of weakness, since it involves a wide range of competencies that must be trained and successfully managed to account for life cycle information in practice.

Indeed, it is important to underline that the integration of LCT into the design and building process represents an upcoming and challenging task for the involved actors, demanding a shift both in thinking and in process. In this context, the data collection framework should be considered as the springboard for a life cycle-oriented practice, to be advanced by follow-up investigations. These concerns, for instance, the technical implementation of the BIM information content, the identification of the possible specific data sources and the exploration of the now available LCT tools. Furthermore, it is worth mentioning that, based on current practice, the data collection framework supports the establishment of the most virtuous life cycle BIM database 
currently feasible. As a result, it can be overcome in the near future in relation to potential new life cycle information and data and it can be simplified in relation to building project complexity.

Consistent with the data collection framework, the progressive implementation of the life cycle information resulting in the life cycle BIM database, can be perceived by building practitioners in two different ways: first, as minimum submission requirements demanded at each design phase for internal purposes, leading to a voluntary process put into effect by the design team to support the development of life cycle oriented practice; and second, as minimum submission requirements for external purposes, followed by a mandatory process in the event that it is assimilated directly by project requirements. In both cases, from a BIM perspective, the life cycle information set by the data collection framework becomes part of the model information evolution, being perceived as a sort of Level Of Development of the information content related to the digital building objects. To this end, those primarily affected are the design team and the manufacturers, who have the chance to achieve directly the BIM objects of their products with the relative life cycle information, thus enhancing data transparency. In this context, defining what to get out of the project information model at the end and at each phase, it is expected that the socalled Employer's Information Requirements extend the typical responsibility matrix and detail the information requirements with the personal worksheets inferred from the data collection framework to build up, over time, the life cycle project-based BIM database.

\section{References}

Becerik-Gerber B, Kensek K (2010) Building information modeling in architecture, engineering, and construction: Emerging research directions and trends. J Profession Issues Eng Educat Practice 136(3):139-147

Boecker et al (2009) The integrative design guide to green building. Wiley, New Jersey

Chirjiv KA, Ben A (2017) Recent developments, future challenges and new research directions in LCA of buildings: a critical review. Renew Sustain Energy Rev 67:408-416

Dalla Valle A, Lavagna M, Campioli A (2018) Matching Life Cycle Thinking and design process in a BIM-oriented working environment. In Paper presented at XII Italian LCA network conference, Messina, 11-12 June 2018

Department of Veterans Affair (2010) A/E submission requirements for VA medical center major new facilities, additions \& renovations

Dupuis M, April A, Lesage P, Forgues D (2017) Method to enable LCA analysis through each level of development of a BIM model. Proc Eng 196:857-863

EC-JRC (2012) ILCD Handbook. Towards more sustainable production and consumption for a resource efficient Europe. European Commission-Joint Research Centre, Luxembourg

EPD: UN CPC 531:2014 Product Category Rules: Buildings

Jiao et al (2013) A cloud approach to unified lifecycle data management in architecture, engineering, construction \& facilities management. Adv Eng Inform 27:173-188

McGraw Hill Construction (2009) The business value of BIM. Getting Building Information Modeling to the Bottom Line. http://bim.construction.com/research/SmartMarket_Report.pdf

Omniclass (2012) A strategy for classifying the built environment. Table 33 - Disciplines 
Pink S, Tutt D, Dainty A (2013) Ethnographic research in the construction industry. Routledge, London and New York

Renz et al (2016) Shaping the future of construction. A Breakthrough in Mindset and Technology, World Economic Forum

Rezgui et al (2011) Past, present and future of information and knowledge sharing in the construction industry. Comput Aided Des 43:502-515

Riese M (2012) Technology-augmented changes in the design and delivery of the built environment. Commun Comput Informat Sci 242:49-69

Rusu D, Popescu S (2018) Decision-making for enhancing building sustainability through life cycle. Appl Math Mech Eng 61:191-202

Succar B, Kassem M (2015) Macro-BIM adoption: conceptual structures. Automat Construct 57:6479

UN environment (2018) Life cycle initiative. http://www.lifecycleinitiative.org

UNI EN 15978:2011 Sostenibilità delle costruzioni. Valutazione della prestazione ambientale degli edifici. Metodo di calcolo

Open Access This chapter is licensed under the terms of the Creative Commons Attribution 4.0 International License (http://creativecommons.org/licenses/by/4.0/), which permits use, sharing, adaptation, distribution and reproduction in any medium or format, as long as you give appropriate credit to the original author(s) and the source, provide a link to the Creative Commons license and indicate if changes were made.

The images or other third party material in this chapter are included in the chapter's Creative Commons license, unless indicated otherwise in a credit line to the material. If material is not included in the chapter's Creative Commons license and your intended use is not permitted by statutory regulation or exceeds the permitted use, you will need to obtain permission directly from the copyright holder. 